\title{
Intravenous iloprost bridging to orthotopic liver transplantation in portopulmonary hypertension
}

\author{
S. Minder*, M. Fischler*, B. Muellhaupt*, M.P. Zalunardo\#, R. Jenni*, P-A. Clavien`, R. Speich*
}

Intravenous iloprost bridging to orthotopic liver transplantation in portopulmonary hypertension. S. Minder, M. Fischler, B. Muellhaupt, M.P. Zalunardo, R. Jenni, P-A. Clavien, R. Speich. (C) ERS Journals Ltd 2004.

ABSTRACT: Portopulmonary hypertension (PPHTN) is associated with poor prognosis and high perioperative mortality after orthotopic liver transplantation.

This study documents the first case of a patient with PPHTN who was successfully bridged to orthotopic liver transplantation with $i$.v. iloprost, a stable prostacyclin analogue. The PPHTN had resolved completely 4 months after successful transplantation.

In conclusion, portopulmonary hypertension is a relative contraindication to orthotopic liver transplantation, which should be attempted only if pulmonary haemodynamics improve with prostanoids. In this context, iloprost may be a valuable alternative to epoprostenol.

Eur Respir J 2004; 24: 703-707.
Depts of *Internal Medicine, \#Anaesthesiology and "Surgery, University Hospital, Zurich, Switzerland.

Correspondence: R. Speich, Dept of Internal Medicine, University Hospital, Raemistrasse 100, CH-8091 Zurich, Switzerland.

Fax: 4112554451

E-mail: klinspr@usz.unizh.ch

Keywords: Epoprostenol, iloprost, liver cirrhosis, liver transplantation, portopulmonary hypertension, pulmonary hypertension

Received: December 22003

Accepted after revision: April 82004
Two distinct pulmonary circulatory syndromes have been described in association with advanced liver disease: 1) hepatopulmonary syndrome, and 2) portopulmonary hypertension (PPHTN) [1-3]. Hepatopulmonary syndrome is characterised by hypoxaemia caused by pulmonary vascular dilatations and direct arteriovenous shunts (table 1). Most centres consider the syndrome to be an indication for orthotopic liver transplantation (OLT) [2]. Complete resolution of the syndrome is well documented [4]. PPHTN is a specific condition characterised by an elevated mean pulmonary arterial pressure $(P \mathrm{pa})$, increased pulmonary vascular resistance (PVR), and a normal pulmonary artery occlusion pressure (PAOP) in the presence of portal hypertension and absence of other potential causes of pulmonary hypertension, such as chronic thromboembolic disease, valvular disease, collagen vascular disease, HIV infection, and ingestion of certain toxins or appetite suppressants. In the World Health Organization (WHO) classification, PPHTN represents a subset of pulmonary arterial hypertension [5]. There are only a few case reports of patients with the coexistence of PPHTN and hepatopulmonary syndrome [1]. Right-to-left intracardiac shunts through a patent foramen ovale, as a cause of hypoxaemia, should be excluded in this situation.
PPHTN is a well-recognised complication of advanced liver disease, and affects $2-5 \%$ of such patients. However, in liver transplant candidates, the prevalence is higher and ranges $4-26 \%$. Many of these patients exhibit high-flow states (normal or low PVR) or increased central blood volume (increased PAOP). Thus, the incidence of true PPHTN (increased PVR) is $\sim 4 \%$ [6-8]. Prognosis is poor, with a mean survival of 15 months after diagnosis [9]. Perioperative mortality in patients who undergo OLT is extremely high, and seems to correlate with the degree of increase in $P$ pa. Although patients with mild-tomoderate PPHTN ( $P$ pa $25-35 \mathrm{mmHg}$ ) can safely undergo transplantation without increased risk [6-8, 10], in patients with a $P$ pa of $35-49 \mathrm{mmHg}$, the perioperative mortality rate is $\sim 50 \%$, and reaches $70-100 \%$ in those with a $P$ pa of $>50 \mathrm{mmHg}$ [10]. The high perioperative mortality results primarily from right ventricular dysfunction. Thus, severe PPHTN has been considered to be a contraindication to OLT. Nevertheless, the reduction in $P$ pa and PVR, as well as the improvement in right ventricular function during continuous infusion of epoprostenol, may facilitate successful OLT [11-15]. The disadvantage of epoprostenol is its very short half-life and the rapid development of tolerance, necessitating increasing doses of the drug to achieve the same effects. Thus, the more stable

Table 1.-Definition of portopulmonary hypertension (PPHTN) and hepatopulmonary syndrome

Portal hypertension $>10 \mathrm{mmHg}$

$P$ pa $>25 \mathrm{mmHg}$ at rest $(>30 \mathrm{mmHg}$ during exercise)

PAOP $<15 \mathrm{mmHg}$

$\mathrm{PVR}^{\#}>120 \mathrm{dyn} \cdot \mathrm{s} \cdot \mathrm{cm}^{-5}$
Chronic liver disease

$\mathrm{Pa}_{\mathrm{a}} \mathrm{O}_{2}<70 \mathrm{mmHg}$ or $\mathrm{PA}-\mathrm{a}, \mathrm{O}_{2}>20 \mathrm{mmHg}$

Intrapulmonary arteriovenous shunts

$P$ pa: mean pulmonary arterial pressure; PAOP: pulmonary artery occlusion pressure; PVR: pulmonary vascular resistance; $P$ a, $\mathrm{O}_{2}$ : arterial oxygen tension; $P$ A-a, $\mathrm{O}_{2}$ : alveolar-arterial oxygen tension gradient. ${ }^{\#}: 80(P$ pa-PAOP $) /$ cardiac output. This criterion helps to distinguish between increased pulmonary arterial pressure due to high-flow (high cardiac output) and hyperdynamic circulatory (normal or low PVR) states and portopulmonary hypertension. ${ }^{\top}$ : detected by contrast echocardiography, lung perfusion scanning or pulmonary angiography. 
prostacyclin analogue iloprost might be an alternative treatment option.

\section{Case report}

In August 1996, a 48-yr-old patient underwent laparotomy for a perforated gastric ulcer. Routine laboratory examinations revealed elevated liver enzyme levels and liver cirrhosis as a result of chronic hepatitis $\mathrm{C}$, and chronic alcohol abuse was subsequently diagnosed. After a second episode of variceal bleeding in January 1998, the patient successfully stopped drinking alcohol. The clinical course was complicated by several episodes of ascites and jaundice, and, in December 1999, the patient was evaluated for OLT. At that time, no contraindications were found. Echocardiography revealed a normal right ventricular systolic pressure (RVSP; $27 \mathrm{mmHg}$ ), measured over right atrial pressure, and the patient was listed for transplantation. In September 2000, a routine control examination revealed a multifocal hepatocellular carcinoma with three nodules, located in segments IV and VIII. Three transarterial segmental hepatic chemoembolisations were performed between September 2000 and July 2001, and they resulted in partial tumour remission.

In January 2001, the patient was admitted for transplantation when a donor organ became available. Induction of anaesthesia was unremarkable, except for right heart catheterisation, which revealed severe pulmonary hypertension with a $P$ pa of $50 \mathrm{mmHg}$. In view of this unexpected major risk factor, the transplantation was cancelled. Further diagnostic work-up excluded diseases of the respiratory system, thromboembolism, heart failure and valvular heart diseases. The alveolar-arterial oxygen tension gradient was $16 \mathrm{mmHg}$ (normal $<20 \mathrm{mmHg}$ ). Thus, severe PPHTN was diagnosed. Not even retrospectively, reviewing the video sequence of the first echocardiographic examination in December 1999, were there any signs of elevated pulmonary arterial pressure, and the examination performed at the same time showed an RVSP of $74 \mathrm{mmHg}$ and the distinctive pattern of severe pulmonary hypertension.

The patient complained only of slight dyspnoea on exertion (WHO functional class II). Analogous to the protocol of KUO et al. [16], invasive haemodynamic testing was performed (table 2), and continuous i.v. therapy with iloprost started at a gradually increasing infusion rate of $\leqslant 200 \mu \mathrm{g} \cdot \mathrm{day}^{-1}$ $\left(1.8 \mathrm{ng} \cdot \mathrm{kg}\right.$ body weight $\left.{ }^{-1} \cdot \mathrm{min}^{-1}\right)$. Iloprost was chosen since it is routinely used instead of epoprostenol in the present authors' pulmonary hypertension programme, primarily because of its longer half-life, its possible lesser tendency to tolerance development, and the need for lower doses and, therefore, lower costs. After 3 months of iloprost infusion, the patient's 6-min walking distance improved, and a significant reduction in RVSP to $<40 \mathrm{mmHg}$ could be achieved.

In August 2001, the patient underwent OLT. The intraoperative course was uneventful. Iloprost was continued throughout the transplant procedure. Cardiac function, monitored by electrocardiography and right heart catheterisation, remained stable and without exacerbation of pulmonary hypertension after reperfusion of the transplanted liver. Low-dose noradrenalin was given for $24 \mathrm{~h}$ to stabilise the systemic blood pressure. Immunosuppressive therapy with tacrolimus was commenced. After reconstitution of liver function, the iloprost dose had to be increased to $300 \mu \mathrm{g} \cdot \mathrm{day}^{-1}$ $\left(2.7 \mathrm{ng} \cdot \mathrm{kg}\right.$ body weight $\left.{ }^{-1} \cdot \mathrm{min}^{-1}\right)$ because of an increase in $P$ pa to $45 \mathrm{mmHg}$.

Postoperative recovery was favourable and without any major complications. The patient was extubated on postoperative day 1 , transferred to the ward on day 3 , and discharged from hospital on day 13. Treatment with iloprost was continued. The explanted cirrhotic liver showed a moderately differentiated hepatocellular carcinoma in the left lobe and two circumscribed completely necrotic areas in the right lobe, as well as signs of chronic hepatitis with minimal inflammatory activity. In December 2001, 4 months after liver transplantation, all echocardiographic signs of pulmonary hypertension had disappeared, and the RVSP was $27 \mathrm{mmHg}$. The patient was completely asymptomatic, and the continuous $i$.v. therapy with iloprost was stopped. The patient is still doing well 25 months after OLT. Echocardiographic results remain normal. Meanwhile, reinfection with hepatitis $\mathrm{C}$ virus has been documented and treatment with pegylated interferon alpha-2a and ribavirin has begun. There are no signs of tumour recurrence.

\section{Discussion}

The first patient with severe PPHTN successfully bridged to OLT with continuous i.v. iloprost, a stable prostacyclin analogue, is presented. Pulmonary hypertension resolved 4 months after successful transplantation and, subsequently, vasodilator therapy could be stopped. The patient's clinical course $>2$ yrs after OLT is excellent, and there is no recurrence of pulmonary hypertension.

Table 2.-Haemodynamic and echocardiographic profile throughout the patient's course, before and after orthotopic liver transplantation (OLT)

\begin{tabular}{|c|c|c|c|c|c|c|}
\hline & \multicolumn{2}{|c|}{ Pre-OLT } & \multicolumn{4}{|c|}{ Post-OLT } \\
\hline & \multirow[t]{2}{*}{ Baseline } & \multirow[t]{2}{*}{ Iloprost $^{\#}$} & \multicolumn{3}{|c|}{ Iloprost $^{\oplus}$} & \multirow[t]{2}{*}{ No therapy } \\
\hline & & & Day 1 & Month 1 & Month 4 & \\
\hline HR beats $\cdot \min ^{-1}$ & 68 & 64 & 80 & 82 & 68 & 70 \\
\hline $\mathrm{BP} \mathrm{mmHg}$ & $104 / 54$ & $100 / 46$ & $120 / 85$ & $130 / 90$ & $130 / 80$ & $120 / 75$ \\
\hline$P$ pa $\mathrm{mmHg}$ & 54 & 38 & 45 & & & \\
\hline PAOP $\mathrm{mmHg}$ & 8 & 10 & 9 & & & \\
\hline Cardiac index $\mathrm{L} \cdot \mathrm{min}^{-1} \cdot \mathrm{m}^{-2}$ & 3.7 & 3.9 & 4.2 & & & \\
\hline PVR dyn $\cdot \mathrm{s} \cdot \mathrm{cm}^{-5}$ & 524 & 302 & 361 & & & \\
\hline $\mathrm{Sv}_{\mathrm{v}, \mathrm{O}_{2}} \%$ & 74 & 77 & 76 & & & \\
\hline RVSP mmHg & 74 & & & 68 & 27 & 29 \\
\hline 6MWD m & 462 & 579 & & 570 & 572 & 582 \\
\hline
\end{tabular}

HR: heart rate; BP: systolic/diastolic blood pressure; Ppa: mean pulmonary arterial pressure; PAOP: pulmonary artery occlusion pressure; PVR: pulmonary vascular resistance; $\mathrm{Sv}_{\mathrm{v}}, \mathrm{O}_{2}$ : mixed venous saturation; RVSP: right ventricular systolic pressure (over right atrial pressure); 6MWD: 6-min walking distance. ${ }^{\#}: 200 \mu \mathrm{g} \cdot$ day $^{-1}$ i.v.; ${ }^{\uparrow}: 300 \mu \mathrm{g} \cdot$ day $^{-1}$ i.v. 
Until the mid-1990s, severe PPHTN was considered to be an absolute contraindication to OLT. When the $P$ pa is $>50 \mathrm{mmHg}$, perioperative mortality is $70-100 \%$ [10]. In 1997 , after encouraging results from the continuous administration of epoprostenol in idiopathic pulmonary arterial hypertension [17], Kuo et al. [18] demonstrated a favourable haemodynamic effect of this treatment in four cases of PPHTN, with a $22-71 \%$ decrease in PVR. One year later, the same group reported the first case undergoing successful OLT after 4 months of preoperative treatment with $i$. v. epoprostenol [11]. The patient was taken off epoprostenol 3 months after transplantation with near normal pulmonary haemodynamics.

To date, only four other cases who bridged to OLT with continuous i.v. epoprostenol have been described (table 3 ) [12-15]. Although one patient died due to right heart failure 28 days after OLT, the other three are alive and successfully weaned from vasodilator therapy.

The novel aspect of the present case is the treatment with continuous infusion of iloprost instead of epoprostenol. Iloprost is a prostacyclin analogue that has several advantages over epoprostenol. Whereas the latter has to be protected from light and needs to be dissolved in a glycine buffer for i.v. administration, iloprost is much more chemically stable. Moreover, iloprost has a biphasic disposition, with longer half-lives of 3-4 and $30 \mathrm{~min}$, in contrast to the half-life of $<5 \mathrm{~min}$ of epoprostenol [19]. In addition, much lower doses of iloprost are needed for a comparable haemodynamic effect [20].

A recent case series has cast doubt on the efficacy of epoprostenol, since six of the 10 patients died after a mean follow-up time of 9 months, at least two of them possibly due to PPHTN after 5 and 6 months, respectively [12]. The same group recently reported a peculiar syndrome of progressive splenomegaly with worsening thrombocytopenia and leukopenia in four patients on continuous i.v. epoprostenol [21]. One of them died as a result of sepsis following splenic embolisation and subsequent splenectomy. Thus, the present finding that iloprost has a comparable effect to that of epoprostenol suggests that iloprost might become a valuable treatment alternative in severe PPHTN.

The excessive perioperative mortality in patients with severe PPHTN undergoing OLT suggests that early diagnosis is crucial. Since, as in the present case, patients with even severe PPHTN are not infrequently asymptomatic [10, 22, 23], and PPHTN is a serious but treatable disorder, screening for pulmonary hypertension plays a key role in the management of OLT candidates. For the detection of pulmonary hypertension, ECG and plain chest radiography are unreliable, as their sensitivity is only $\sim 60 \%$ and $\sim 80 \%$, respectively [23]. Transthoracic echocardiography is a sensitive noninvasive diagnostic method. It is considered the screening modality of choice for all forms of pulmonary hypertension, including PPHTN. In a study of 165 OLT candidates [24], the sensitivity and specificity of RVSP at a relatively low cut-off of $>30 \mathrm{mmHg}$ (including a right atrial pressure of $5 \mathrm{mmHg}$ ), with respect to a $P$ pa of $>25 \mathrm{mmHg}$, were 100 and $96 \%$, respectively. However, half of these patients with invasively confirmed PPHTN had a $P$ pa of $<40 \mathrm{mmHg}$ and could thus undergo OLT without additional treatment. In another study of 74 OLT candidates using a higher RVSP cut-off of $\geqslant 50 \mathrm{mmHg}$, sensitivity and specificity were 97 and $72 \%$, respectively [25]. Only one patient with an RVSP of $<50 \mathrm{mmHg}$ had a $P$ pa of $\geqslant 35 \mathrm{mmHg}$, but the invasively determined systolic pulmonary arterial pressure was only $55 \mathrm{mmHg}$. Thus, Doppler echocardiography is an accurate screening test, and all OLT candidates with an RVSP of $\geqslant 50 \mathrm{mmHg}$ should undergo right heart catheterisation. Although rare, PPHTN can develop after evaluation for OLT, as was the case in the present patient. In their large series, COLLE et al. [24] describe three patients who developed PPHTN within only 3-5 months after the initial evaluation for OLT. In their retrospective review of 43 patients, KROWKA et al. [10] found that, in 65\%, PPHTN was diagnosed in the operating room immediately prior to OLT. Thus, regular echocardiographic examinations of OLT candidates on the waiting list are necessary, although the optimal screening frequency remains to be determined. In accordance with the Mayo Clinic Liver Transplantation Program (M.J. Krowka, Division of Pulmonary and Critical Care, The Mayo Clinic, Rochester, MN, USA, personal communication), the patients on the current authors' waiting list are screened every 12 months if the first echocardiography is normal, and every 6 months if the RVSP is $35-50 \mathrm{mmHg}$. Patients with an RVSP of $>50 \mathrm{mmHg}$ undergo right heart catheterisation and initiation of vasodilator therapy, with the aim of decreasing $P$ pa to $<35-40 \mathrm{mmHg}$ and PVR to $<400 \mathrm{dyn} \cdot \mathrm{s} \cdot \mathrm{cm}^{-5}$ with good cardiac output before listing them for OLT.

Since the aetiology of PPHTN is unknown [26], it is difficult to predict whether pulmonary hypertension will resolve after OLT. Literature data indicate that, as in the present case, almost all patients with PPHTN show improved or normalised pulmonary artery pressures within 6 months after OLT [27-30], but this may take up to 2 yrs [31]. In literature reviews, it was found that 19 out of $25(76 \%)$ patients ever transplanted for PPHTN showed improved or resolved pulmonary hypertension $[6,8,10]$. In individual cases, persistence $[6,14,32,33]$, progression $[6,34]$, recurrence [35] or even de novo evolution [36] of pulmonary hypertension after OLT have been observed. A comparison of the preoperative haemodynamics revealed that patients who showed improved or resolved pulmonary hypertension had

Table 3. - Pulmonary haemodynamics and outcomes of patients with portopulmonary hypertension treated with prostaglandins prior to orthotopic liver transplantation (OLT)

\begin{tabular}{|c|c|c|c|c|c|c|c|c|c|c|c|}
\hline \multirow{3}{*}{$\begin{array}{l}\text { First author } \\
\text { [Ref.] }\end{array}$} & \multicolumn{2}{|c|}{ Baseline } & \multicolumn{2}{|c|}{ Preoperative } & \multicolumn{2}{|c|}{ Postoperative } & \multicolumn{3}{|c|}{ Epoprostenol } & \multirow[t]{3}{*}{ Status } & \multirow{3}{*}{$\begin{array}{l}\text { Survival } \\
\text { months }\end{array}$} \\
\hline & \multirow{2}{*}{\multicolumn{2}{|c|}{$\begin{array}{cc}P \text { pa } & \text { PVR } \\
\mathrm{mmHg} \mathrm{dyn} \cdot \mathrm{s} \cdot \mathrm{cm}^{-5}\end{array}$}} & \multirow{2}{*}{$\begin{array}{c}P \text { pa } \\
\mathrm{mmHg}\end{array}$} & \multirow{2}{*}{$\begin{array}{c}\text { PVR } \\
\text { lyn } \cdot s \cdot \mathrm{cm}^{-5}\end{array}$} & \multirow{2}{*}{$\begin{array}{c}P \text { pa } \\
\mathrm{mmHg}\end{array}$} & \multirow{2}{*}{$\begin{array}{c}\text { PVR } \\
\mathrm{yn} \cdot \mathrm{s} \cdot \mathrm{cm}^{-5}\end{array}$} & \multirow{2}{*}{$\begin{array}{c}\text { Dose } \\
\mathrm{ng} \cdot \mathrm{kg} \cdot \mathrm{min}^{-1}\end{array}$} & \multicolumn{2}{|c|}{ Therapy duration months } & & \\
\hline & & & & & & & & Pre-OLT & Post-OLT & & \\
\hline PLOTKIN [11] & 47 & 678 & 26 & 271 & 28 & 253 & 23 & 4 & 3 & Alive & 3 \\
\hline KROWKA [12] & 39 & 358 & 40 & 187 & NA & NA & 11 & 3 & 4 & Alive & 8 \\
\hline RAMSAY [13] & 38 & 587 & 29 & 193 & NA & NA & 7 & 1 & 3 & Alive & 3 \\
\hline TAN [14] & 48 & 472 & 33 & 248 & 32 & 355 & 50 & 36 & 10 & Alive & 12 \\
\hline MAIR [15] & 46 & 960 & 39 & 240 & 47 & 520 & 6 & & & Died after OLT & 1 \\
\hline Present case & 54 & 524 & 38 & 302 & 45 & 361 & Iloprost $^{\#}$ & 8 & 3 & Alive & 25 \\
\hline
\end{tabular}

Ppa: mean pulmonary arterial pressure; PVR: pulmonary vascular resistance; NA: not applicable. \#: see Case report section. 
a lower $P$ pa $(43 \mathrm{mmHg} ; 95 \%$ confidence interval (CI) $39-47 \mathrm{mmHg}$ ) compared with those who did not (51 mmHg; 95\% CI 42-61 mmHg). This difference, however, was not significant $(\mathrm{p}=0.1)$. Thus, owing to the large overlap between the two groups, the individual postoperative course cannot be predicted from the severity of PPHTN. It is noteworthy that the present case represents the one with the highest preoperative $P$ pa of those who showed improved or normalised haemodynamics postoperatively.

In conclusion, it has been shown that iloprost is a valuable alternative for the successful bridging to orthotopic liver transplantation of patients with severe portopulmonary hypertension. Regular echocardiographic screening of orthotopic liver transplantation candidates on the waiting list is mandatory, since portopulmonary hypertension may develop at any time.

Acknowledgements. The candid feedback provided to the authors by M.J. Krowka (Division of Pulmonary and Critical Care, The Mayo Clinic, Rochester, MN, USA) during the preparation of this manuscript is gratefully acknowledged.

\section{References}

1. Herve P, Lebrec D, Brenot F, et al. Pulmonary vascular disorders in portal hypertension. Eur Respir J 1998; 11: $1153-1166$.

2. Krowka MJ. Hepatopulmonary syndrome and portopulmonary hypertension. Curr Treat Options Cardiovasc Med 2002; 4: 267-273.

3. Naeije R. Hepatopulmonary syndrome and portopulmonary hypertension. Swiss Med Wkly 2003; 133: 163-169.

4. Krowka MJ, Porayko MK, Plevak DJ, et al. Hepatopulmonary syndrome with progressive hypoxemia as an indication for liver transplantation: case reports and literature review. Mayo Clin Proc 1997; 72: 44-53.

5. Runo JR, Loyd JE. Primary pulmonary hypertension. Lancet 2003; 361: 1533-1544.

6. Ramsay MA, Simpson BR, Nguyen AT, Ramsay KJ, East C, Klintmalm GB. Severe pulmonary hypertension in liver transplant candidates. Liver Transpl Surg 1997; 3: 494-500.

7. Castro M, Krowka MJ, Schroeder DR, et al. Frequency and clinical implications of increased pulmonary artery pressures in liver transplant patients. Mayo Clin Proc 1996; 71: 543551.

8. Starkel P, Vera A, Gunson B, Mutimer D. Outcome of liver transplantation for patients with pulmonary hypertension. Liver Transpl 2002; 8: 382-388.

9. Robalino BD, Moodie DS. Association between primary pulmonary hypertension and portal hypertension: analysis of its pathophysiology and clinical, laboratory and hemodynamic manifestations. J Am Coll Cardiol 1991; 17: 492-498.

10. Krowka MJ, Plevak DJ, Findlay JY, Rosen CB, Wiesner RH, Krom RA. Pulmonary hemodynamics and perioperative cardiopulmonary-related mortality in patients with portopulmonary hypertension undergoing liver transplantation. Liver Transpl 2000; 6: 443-450.

11. Plotkin JS, Kuo PC, Rubin LJ, et al. Successful use of chronic epoprostenol as a bridge to liver transplantation in severe portopulmonary hypertension. Transplantation 1998; 65: $457-459$

12. Krowka MJ, Frantz RP, McGoon MD, Severson C, Plevak DJ, Wiesner RH. Improvement in pulmonary hemodynamics during intravenous epoprostenol (prostacyclin): a study of 15 patients with moderate to severe portopulmonary hypertension. Hepatology 1999; 30: 641-648.

13. Ramsay MA, Spikes C, East CA, et al. The perioperative management of portopulmonary hypertension with nitric oxide and epoprostenol. Anesthesiology 1999; 90: 299-301.

14. Tan HP, Markowitz JS, Montgomery RA, et al. Liver transplantation in patients with severe portopulmonary hypertension treated with preoperative chronic intravenous epoprostenol. Liver Transpl 2001; 7: 745-749.

15. Mair P, Kaehler CH, Pomaroli A, Schwarz B, Vogel W, Margreiter R. Orthotopic liver transplantation in a patient with severe portopulmonary hypertension. Acta Anaesthesiol Scand 2001; 45: 513-518.

16. Kuo PC, Plotkin JS, Gaine S, et al. Portopulmonary hypertension and the liver transplant candidate. Transplantation 1999; 67: 1087-1093.

17. Barst RJ, Rubin LJ, Long WA, et al. A comparison of continuous intravenous epoprostenol (prostacyclin) with conventional therapy for primary pulmonary hypertension. $N$ Engl J Med 1996; 334: 296-301.

18. Kuo PC, Johnson LB, Plotkin JS, Howell CD, Bartlett ST, Rubin LJ. Continuous intravenous infusion of epoprostenol for the treatment of portopulmonary hypertension. Transplantation 1997; 63: 604-606.

19. Krause W, Krais T. Pharmacokinetics and pharmacodynamics of the prostacyclin analogue iloprost in man. Eur J Clin Pharmacol 1986; 30: 61-68.

20. Higenbottam TW, Butt AY, Dinh-Xaun AT, Takao M, Cremona G, Akamine S. Treatment of pulmonary hypertension with the continuous infusion of a prostacyclin analogue, iloprost. Heart 1998; 79: 175-179.

21. Findlay JY, Plevak DJ, Krowka MJ, Sack EM, Porayko MK. Progressive splenomegaly after epoprostenol therapy in portopulmonary hypertension. Liver Transpl Surg 1999; 5: $362-365$

22. Murata K, Shimizu A, Takase K, Nakano T, Tameda Y. Asymptomatic primary pulmonary hypertension associated with liver cirrhosis. J Gastroenterol 1997; 32: 102-104.

23. Yang YY, Lin HC, Lee WC, et al. Portopulmonary hypertension: distinctive hemodynamic and clinical manifestations. J Gastroenterol 2001; 36: 181-186.

24. Colle IO, Moreau R, Godinho E, et al. Diagnosis of portopulmonary hypertension in candidates for liver transplantation: a prospective study. Hepatology 2003; 37: 401409.

25. Kim WR, Krowka MJ, Plevak DJ, et al. Accuracy of Doppler echocardiography in the assessment of pulmonary hypertension in liver transplant candidates. Liver Transpl 2000; 6: 453-458.

26. Budhiraja R, Hassoun PM. Portopulmonary hypertension: a tale of two circulations. Chest 2003; 123: 562-576.

27. De Wolf AM, Scott VL, Gasior T, Kang Y. Pulmonary hypertension and liver transplantation. Anesthesiology 1993; 78: 213-214.

28. Koneru B, Ahmed S, Weisse AB, Grant GP, McKim KA Resolution of pulmonary hypertension of cirrhosis after liver transplantation. Transplantation 1994; 58: 1133-1135.

29. Losay J, Piot D, Bougaran J, et al. Early liver transplantation is crucial in children with liver disease and pulmonary artery hypertension. J Hepatol 1998; 28: 337-342.

30. Schott R, Chaouat A, Launoy A, Pottecher T, Weitzenblum E. Improvement of pulmonary hypertension after liver transplantation. Chest 1999; 115: 1748-1749.

31. Levy MT, Torzillo P, Bookallil M, Sheil AG, McCaughan GW. Case report: delayed resolution of severe pulmonary hypertension after isolated liver transplantation in a patient with cirrhosis. J Gastroenterol Hepatol 1996; 11: 734-737.

32. Mandell MS, Duke J. Nitric oxide reduces pulmonary hypertension during hepatic transplantation. Anesthesiology 1994; 81: 1538-1542.

33. Prager MC, Cauldwell CA, Ascher NL, Roberts JP, Wolfe CL. Pulmonary hypertension associated with liver disease is not reversible after liver transplantation. Anesthesiology 1992; 77: 375-378. 
34. Rafanan AL, Maurer J, Mehta AC, Schilz R. Progressive portopulmonary hypertension after liver transplantation treated with epoprostenol. Chest 2000; 118: 1497-1500.

35. Kett DH, Acosta RC, Campos MA, Rodriguez MJ, Quartin AA, Schein RM. Recurrent portopulmonary hypertension after liver transplantation: management with epoprostenol and resolution after retransplantation. Liver Transpl 2001; 7: 645-648.

36. Koneru B, Fisher A, Wilson DJ, Klein KM, de la Torre AN, Seguel J. De novo diagnosis of portopulmonary hypertension following liver transplantation. Am J Transplant 2002; 2 : 883-886. 